\title{
Beneficial Effects of a 1-Year Lifestyle Intervention on Metabolic Abnormalities in Overweight and Obese Schoolchildren in Sousse Tunisia: A Pre-Post Quasi- Experimental Study with Control Group
}

Jihene Maatoug ${ }^{1}$, , Jihene Sahli ${ }^{1}$, Sihem B. Fredj ${ }^{1}$, Rim Ghammem ${ }^{1}$, Imed Harrabi ${ }^{1}$, Firas Chouikha ${ }^{1}$, Lamia Boughammoura $^{2}$, Slim Slama ${ }^{3}$, Nathalie F. Lambert ${ }^{4}$, Hassen Ghannem ${ }^{1}$

${ }^{1}$ Department of Epidemiology, University Hospital Farhat Hached Sousse, Tunisia

${ }^{2}$ Department of Pediatrics, University Hospital Farhat Hached Sousse, Tunisia

${ }^{3}$ World Health Organization Office Eastern Mediterranean Region, Non-Communicable Diseases Management Unit, Cairo, Egypt

${ }^{4}$ Pediatric Cardiology Unit, Department of Child and Adolescent University Hospitals of Geneva, University of Geneva,

Geneva, Switzerland

Received: July 07, 2015; Accepted: August 22, 2015; Published: November 19, 2015

*Corresponding author: Jihene Maatoug, Department of Epidemiology, University Hospital Farhat Hached, Sousse, Tunisia, E-mail: jihenmaatoug3107@gmail.com

\begin{abstract}
Introduction: The prevalence of obesity in children has increased worldwide during the most recent decades. In this context, we have conducted this study in the purpose to investigate changes in metabolic syndrome in overweight and obese adolescents after one year of multidisciplinary lifestyle intervention in schools in the region of Sousse, Tunisia.

Methods: We conducted a quasi-experimental study between 2012 and 2014 to investigate the effectiveness of a school-based intervention to reduce metabolic abnormalities in obese and overweight children aged 11 to 16 years in Sousse, Tunisia.

Results: Intervention group was composed of 317 and 225 schoolchildren respectively at pre and post assessment. The control group was composed of 268 and 180 schoolchildren. The mean of body mass index Z-score and waist circumference decreased significantly from pre- intervention to post- intervention both in intervention and control groups $(p<.001)$. Prevalence of metabolic syndrome in intervention group decreased from $7.2 \%$ to $1.8 \%$ among all participants $(p=0.10)$. In the control group, it increased from $4 \%$ to $7.9 \%$.
\end{abstract}

Conclusion: A lifestyle intervention in schools could be effective to prevent obesity complications, but sustainability needs collaboration between the ministry of health and education.

Keywords: Children; Obesity; Metabolic syndrome; Management Prevention

\section{Introduction}

The prevalence of obesity in children has increased worldwide during the most recent decades [1]. Up to $20 \%$ of children in several Western European countries are overweight, and the fattest children seem to be becoming even more obese $[1,2]$. This problem is also increasing in developing countries [3]. In fact, over the last 20 years, the rates of obesity has tripled largely due to decreased physical activity and increased consumption of energy-dense foods [3]. Tunisia is facing the same phenomenon with the epidemiological transition $[4,5]$. The current prevalence of overweight and obesity was respectively $23.7 \%$ and $5.1 \%$ among girls and $21.1 \%$ and $7 \%$ among boys in the region of Sousse [6]. Another study demonstrated the tracking of obesity and upper values of BMI among adolescents after four years of follow-up [7].

The increases in BMI during childhood may be related to the development and acceleration of adverse cardiometabolic risk factors, such as hypertension, dyslipidemia (high triglycerides and low high-density lipoprotein (HDL) cholesterol), hyperinsulinemia and glucose intolerance, known as Metabolic Syndrome (MS) [8].

The frequency of MS was $34.4 \%$ among obese children aged between 6 to 18 years in Tunisia [9].

This childhood epidemic of obesity and its health-related consequences in adolescents should be a clinical and public health priority. However, this major public health problem cannot be managed solely in clinical settings [10]. Furthermore, a multidisciplinary behavioral therapy can produce a significant and clinically meaningful reduction in overweight in children and adolescents [11]. Schools are an ideal site to intervene with children for the management of obesity and reduce metabolic syndrome among this high-risk population. A school-based, multi-component physical activity intervention was effective 
to decreasing levels of BMI, skinfold thickness, fasting glucose and increasing the duration of moderate and vigorous physical activity [12]. The majority of children are enrolled in schools and this provides access to children and enables repeated exposure to health promotion interventions [13].

Therefore, the purpose of this project was to investigate changes in metabolic syndrome in overweight and obese adolescents after one year of multidisciplinary lifestyle intervention in schools in the region of Sousse, Tunisia.

\section{Methods}

\section{Study design}

We conducted a quasi-experimental study between 2012 and 2014 to investigate the effectiveness of a school-based intervention to change lifestyle habits and consequently reduce metabolic abnormalities in obese and overweight children in Sousse, Tunisia. The intervention group was located in four schools in the delegation of Sousse Jawhara and Sousse Erriadh and control group was located in two schools in the delegation of Msaken (Table 1).

Sample size estimates were based on a significance level of 0.05 and $80 \%$ power to detect a difference between groups of 0.15 in BMI Z-score after the one-year intervention. Assuming a failure to consent rate of $10 \%$ (not eligible as well as declining to participate) and a dropout rate of 10\%, 250 participants in each group were needed. All overweight and obese schoolchildren enrolled in $7^{\text {th }}$ and $8^{\text {th }}$ grade in selected colleges were invited to participate to the study.

\section{Definition of variables}

Body Mass Index (BMI) was calculated as weight (kg)/ height ${ }^{2}\left(\mathrm{~m}^{2}\right)$ and z-scores were derived using the World Health Organization references [14]. Overweight was defined as BMI between 1 and 1.99 SD and obesity above 2 SD. Metabolic syndrome was defined according to the International Diabetes Federation (IDF) criteria [15].

\section{Intervention program}

Before the beginning of the project, we contacted directors of all participant colleges in an intervention group to have their consent and evaluate their needs. We offered equipment for physical activity to schools to improve this activity for excess weight children. The project team participating in the intervention was composed of medical doctors (general practitioner, epidemiologist and pediatricians), dieticians, physical activity teachers and psychologist. During the intervention, recruited overweight and obese school adolescents participated to an integrative approach including cognitive behavioral techniques based on CONTREPOIDS ${ }^{\odot}$ program [16] which was developed according to the current evidence on obesity treatment [17]. There were been two intervention strategies: A group intervention for all recruited children (overweight and obese) and an additional individual intervention for obese children who require an intensive therapy. Overweight and obese adolescents in intervention schools were invited to participate to group sessions including 7 to15 subjects. Three types of group sessions were been organized for overweight and obese participants.

- First collective session animated by a dietician in schools: healthy diet for overweight and obese children.

- Second Collective session animated by a psychologist in schools to improve self esteem among overweight and obese children.

- Third collective session animated by a medical doctor about snacking for overweight and obese children.

The individual intervention was composed of four consultations during the program. The first consultation targeted all participants (overweight and obese) and the other consultations targeted only obese participants.

- The first advice took place just after data collection about eating habits and physical activity. It concerns both overweight and obese participants.

- Second Individual consultation with a psychologist: assessment of psychological status (screening of depression or low self esteem level) and psychological support for obese participants in intervention group. In the case of problem, the children were addressed for psychological care.

- Third individual consultation with the dietician (for obese children): personalized healthy diet for each obese participant according to his eating habits and BMI.

- Fourth individual consultation for obese children with pediatrician: screening of causes for obesity such as hypothyroidism and/or complication of obesity; education and motivation to follow a healthy diet and regular physical activity.

Program of twice a week additional physical activity sessions in schools coached by physical activity teachers for overweight and obese children: Physical teachers confirmed that they continue to deliver $2 \mathrm{~h}$ per week of physical activity to the enrolled students if they come to the session.

We collected biometric measures such as height, weight and waist circumference. Body weight was recorded to the nearest $0.1 \mathrm{~kg}$ using portable electronic scale Beurer ps 07. Standing height was measured with the participants in bare feet to the nearest $0.5 \mathrm{~cm}$. Waist circumference was measured to the nearest $0.1 \mathrm{~cm}$ using a non stretchable standard tape measure. The measurement was been taken over a light article of clothing, just above the uppermost lateral border of the right Ilium, at the end of a normal expiration. Blood pressure was measured with Omron digital blood pressure monitor at rest. Plasma glucose, total cholesterol, LDL and HDL-cholesterol and triglyceride concentrations were measured by enzymatic methods among all participants. Plasma Insulin level was measured only among obese participants. Blood samples were collected in the morning and after overnight fasting.

In the control group, we did not intervene during the study. 
Beneficial Effects of a 1-Year Lifestyle Intervention on Metabolic Abnormalities in Overweight and Obese Schoolchildren in Sousse Tunisia: A Pre-Post Quasi-Experimental Study with Control Group

Table 1: Lifestyle intervention program for weight management among overweight and obese schoolchildren in Sousse, Tunisia, $2012-2014$.

\begin{tabular}{|c|c|c|c|}
\hline Session & Target population & Session conducted by & Topics \\
\hline $\begin{array}{l}\text { First individual } \\
\text { consultation }\end{array}$ & $\begin{array}{l}\text { Overweight and } \\
\text { obese participants }\end{array}$ & $\begin{array}{l}\text { Medical doctor and } \\
\text { dietician }\end{array}$ & $\begin{array}{l}\text { First advice about healthy eating and } \\
\text { physical activity promotion }\end{array}$ \\
\hline $\begin{array}{l}\text { Second individual } \\
\text { consultation }\end{array}$ & Obese participants & Psychologist & $\begin{array}{l}\text { Assessment of psychological status } \\
\text { and psychological support }\end{array}$ \\
\hline $\begin{array}{l}\text { Third individual } \\
\text { consultation }\end{array}$ & Obese participants & Dietician & Personalized healthy diet \\
\hline First collective session & $\begin{array}{l}\text { Overweight and } \\
\text { obese participants }\end{array}$ & Dietician & Principles of healthy diet \\
\hline $\begin{array}{l}\text { Second collective } \\
\text { session }\end{array}$ & $\begin{array}{l}\text { Overweight and } \\
\text { obese participants }\end{array}$ & Psychologist & Improve self esteem \\
\hline Third collective session & $\begin{array}{l}\text { Overweight and } \\
\text { obese participants }\end{array}$ & Medical doctor & Snacking \\
\hline
\end{tabular}

We just referred overweight and obese children to school medical doctor.

\section{Outcomes measures}

We collected data before and at the end of the intervention both in intervention and control groups.

\section{Statistical analyzes}

We used SPSS v.10.0 Software for data capture and analysis. A $p<0.05$ was considered statistically significant for all tests. We used paired sample t test and Chi square MacNemar test respectively to compare means and percentages at pre and post assessment in each group.

\section{Ethical consideration}

The protocol was approved by the Ethical Committee of the University Hospital Farhat Hached. We obtained children and parents free, informed consent before the participation to the study. In the control area, all screened obese and overweight schoolchildren are been addressed to school medical doctor with the result of biomedical measures for potential management. We offered a delayed intervention in the control group after the end of the project.

\section{Results}

The intervention group was composed of 317 and 225 overweight and obese schoolchildren respectively at pre and post assessment. The control group was composed of 268 and 180 overweight and obese schoolchildren respectively at pre and post assessment (figure 1).

The mean of BMI Z-score of drop out participants was $1.86 \pm 0.5$ vs $1.88 \pm 0.5$ among those who were present at post assessment (after one year intervention) in intervention group $(P=0.79)$. In control group, the mean of BMI Z score among drop out participants was $1.78 \pm 0.6$ vs $1.86 \pm 0.6$ among those who were present at follow up $(P=.33)$. The mean age of participants was respectively $13.2 \pm 0.98$ and $13.6 \pm 0.96$ years in intervention and control groups. The proportion of girls was $55.7 \%$ and $60.1 \%$ in the intervention and control group.

The means of Body mass index (BMI) was 25. $46 \pm 3.2$ in intervention group with $57.7 \%$ of overweight. It was $25.9 \pm 3.9$ in control group with $51.6 \%$ of overweight. Overweight represented $48.4 \%$ among boys and $58 \%$ among girls $(P=0.1)$ in intervention group. In control group it represented $57.4 \%$ among boys and

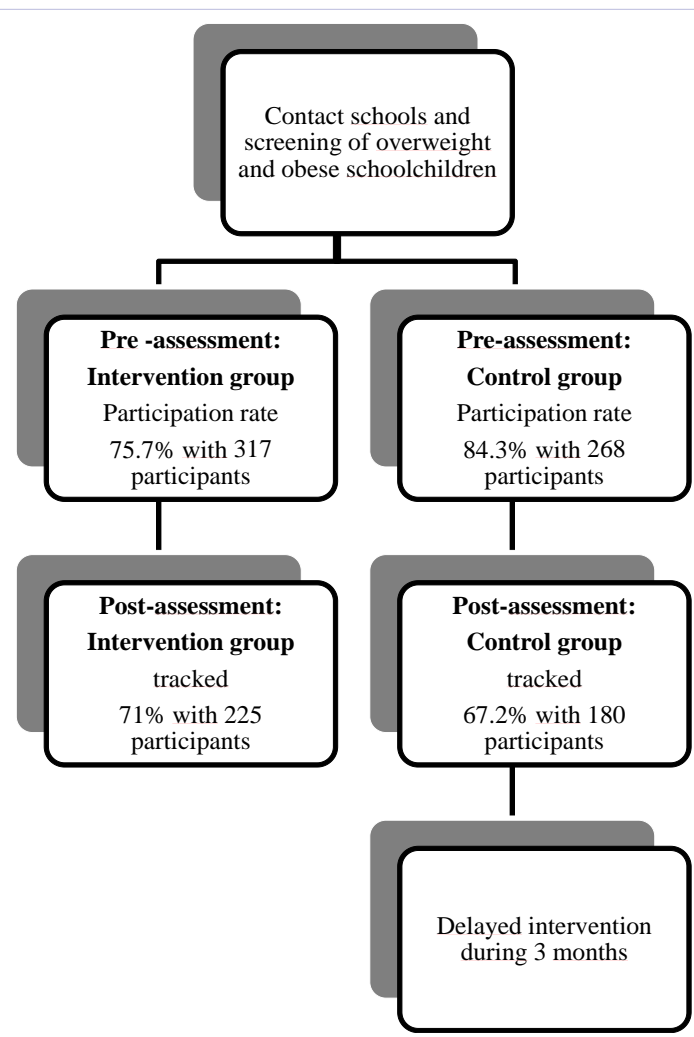

Figure 1: Participation rate of school children at pre and post assessment in the lifestyle intervention on metabolic abnormalities in overweight and obese schoolchildren in Sousse Tunisia, 2012-2014. 


\section{6\% among girls $(P=0.7)$.}

The mean of Body mass index Z-score and waist circumference decreased significantly from pre-intervention to post-intervention both in intervention and control groups. Systolic blood pressure (SBP) decreased in intervention group significantly from 117.8 to $115.2 \mathrm{mmHg}(P=0.01)$ (Table 2).

Blood glucose and insulin level decreased in intervention group and increased significantly in control group. Triglyceride, total cholesterol and LDL cholesterol decreased significantly in intervention group. In control group, only LDL cholesterol decreased significantly (Table 3 ).

Prevalence of metabolic syndrome in intervention group was $7.2 \%$ in all participants, with $11.5 \%$ among obese and $3.4 \%$ among overweight. At the end of the intervention, it decreased to $1.8 \%$ among all participants $(P=0.10)$. In control group, metabolic syndrome was present among $3 \%$ of participants with $4 \%$ and $2 \%$ respectively among obese and overweight. At post assessment, it increased to 5\% among all participants (Table 4).

\section{Discussion}

This school-based lifestyle intervention for excess weight management reduced the prevalence of metabolic syndrome among schoolchildren and improves metabolic parameters. To our knowledge, this is the first multidisciplinary intervention conducted in school settings to manage excess weight in our country. Even though we faced a lot of difficulties in the implementation of this intervention study mainly due to the busy schedule of children, inappropriate environment and lack of motivation of some participants, we were able to demonstrate the feasibility of such intervention.

Schools, where children and adolescents spend the majority of their time, are promising venues for intervention work [18]. A report of Institute of Medicine cited that schools as a "national focal point" could address obesity in children and adolescents [19]. As several systematic reviews demonstrate, however, there is a paucity of obesity intervention research in school settings $[20,21]$.

Some authors proposed a school-based health centers that have several compelling features for a successful lifestyle intervention program to treat overweight/obesity and prevent development of metabolic syndrome [22]. In these schools, clinicians have more access to adolescents than community health care providers; adolescents have better compliance and follow up in school-based clinics; and it's possible to focus on early identification of high-risk problems [22-24]. Conducting research in partnership with the school-based health centers, the school administration, the students, and their families poses a set of logistical and study design challenges [25].

A recent systematic review has reported that lifestyle interventions incorporating dietary and exercise components with or without behavior therapy would lead to improvement of weight and cardio-metabolic outcomes among children [26-27].

Table 2: Evolution of the anthropometric parameters before and after the intervention conducted in the region of Sousse to manage obesity among schoolchildren, 2012-2014.

\begin{tabular}{|l|l|l|l|l|l|l|}
\hline & \multicolumn{3}{l}{ Intervention group } & \multicolumn{2}{l|}{ Control group } & \\
\hline & $\begin{array}{l}\text { Pre intervention } \\
\text { Mean (SD) }\end{array}$ & $\begin{array}{l}\text { Post intervention } \\
\text { Mean (SD) }\end{array}$ & p-value & $\begin{array}{l}\text { Pre intervention } \\
\text { Mean (SD) }\end{array}$ & $\begin{array}{l}\text { Post intervention } \\
\text { Mean (SD) }\end{array}$ & p-value \\
\hline BMI Z-score & $1.88(0.5)$ & $1.75(0.6)$ & $<0.001$ & $1.86(0.6)$ & $1.67(0.7)$ & $<0.001$ \\
\hline $\begin{array}{l}\text { Waist circumference } \\
\text { (cm) }\end{array}$ & $89.5(9.4)$ & $93.9(10.3)$ & $<0.001$ & $88.9(10.9)$ & $83.5(10.5)$ & $<0.001$ \\
\hline SBP (mmHg) & $117.8(11.1)$ & $115.2(12.7)$ & 0.01 & $115.9(11.3)$ & $117.0(11.5)$ & 0.31 \\
\hline DBP (mmHg) & $68.2(10.2)$ & $68.2(13.9)$ & 0.99 & $69.3(10.6)$ & $68.1(13.6)$ & 0.31 \\
\hline A & & & &
\end{tabular}

Abbreviations: BMI: Body mass index; SBP: Systolic blood pressure; DBP: Diastolic blood pressure; SD: Standard deviation

Table 3: Evolution of the metabolic parameters before and after the intervention conducted in the region of Sousse to manage obesity among schoolchildren 2012-2014.

\begin{tabular}{|l|l|l|l|l|l|l|}
\hline & \multicolumn{2}{l}{ Intervention group } & \multicolumn{2}{l|}{ Control group } & \multicolumn{2}{l|}{ Pre-intervention Mean } \\
& $\begin{array}{l}\text { Pre-intervention Mean } \\
\text { (SD) }\end{array}$ & $\begin{array}{l}\text { Post-intervention } \\
\text { Mean (SD) }\end{array}$ & p-value & $\begin{array}{l}\text { Post-intervention } \\
\text { Mean (SD) }\end{array}$ & palue \\
\hline Glucose & $5(0.6)$ & $4.96(0.3)$ & 0.30 & $4.7(0.36)$ & $5.1(1.1)$ & 0.001 \\
\hline Triglycerides & $0.95(0.48)$ & $0.78(0.36)$ & $<0.001$ & $0.83(0.34)$ & $0.4)$ & 0.58 \\
\hline Total cholesterol & $4.1(0.8)$ & $3.7(0.8)$ & $<0.001$ & $4(0.7)$ & $4(0.8)$ & 0.83 \\
\hline LDL cholesterol & $2.5(0.8)$ & $2.2(0.73)$ & $<0.001$ & $2.4(0.7)$ & $2.3(0.7)$ & 0.02 \\
\hline HDL cholesterol & $1.21(0.3)$ & $1.23(0.3)$ & 0.43 & $1.25(0.26)$ & $1.3(0.3)$ & 0.005 \\
\hline Insulin & $9.1(4.8)$ & $10.3(4.9)$ & 0.10 & $8.6(6.2)$ & $13.5(5.2)$ & $<0.001$ \\
\hline
\end{tabular}

Abbreviations: HDL: High Density Lipoprotein; LDL: Low Density Lipoprotein; SD: Standard Deviation 
Beneficial Effects of a 1-Year Lifestyle Intervention on Metabolic Abnormalities in Overweight and Obese Schoolchildren in Sousse Tunisia: A Pre-Post Quasi-Experimental Study with Control Group

Table 4: Evolution of metabolic syndrome among overweight and obese participants in intervention and control groups.

\begin{tabular}{|l|l|l|l|l|}
\hline & \multicolumn{2}{|l|}{ Intervention group } & \multicolumn{2}{l|}{ Control group } \\
\hline & Pre-assessment n (\%) & Post-assessment n (\%) & Pre-assessment $\mathbf{n}(\%)$ \\
\hline Obese & $6(11.5)$ & $2(3.8)$ & $3(6.1)$ & $7(14.2)$ \\
\hline Overweight & $2(3.4)$ & $0(0.0)$ & $1(2.0)$ & $1(2.0)$ \\
\hline Total & $8(7.2)$ & $2(1.8)$ & $4(4.0)$ & $8(7.9)$ \\
\hline
\end{tabular}

Some interventions used out of school activities and involvement of parents [28]. Both these approaches were found to be beneficial. The majority of the interventions focused on individual level behavior change approaches and few addressed broader policy and environmental level changes [28]. The majority of the interventions utilized existing teachers for implementation of the interventions [28].

Nevertheless, almost $80 \%$ of pediatricians report frustration with their ability to make an impact on obesity [29] and many providers feel they do not have the tools to effectively address lifestyle modification for weight loss [30]. A recent Cochrane review evaluated sixty-four randomized controlled trials in community setting of educational, behavioral and health promotion interventions for childhood obesity [31]. Authors concluded that comprehensive interventions with family implication to promote healthy diet and physical activity with psycho-social support were more effective than those targeting only the obese child [31].

In our study, we observed a significant decrease of BMI Z-score both in intervention and control groups. We think that it could due to Hawthorne effect. In fact, we observed a high level of motivation among control group to lose weight. Indeed, the majority of interventional studies have shown that without treatment, BMI z-scores increases [31].

In other hand, we recognize that this intervention didn't show a significant decrease of MS in intervention group, nevertheless it increased in control group. The main limitation of this study was the absence of randomization and a quasi-experimental design couldn't insure the intervention effect.

A lifestyle intervention in schools is feasible and could be effective to help health professionals in decreasing obesity and preventing its complications. However, the implication and collaboration between the ministry of health and education is needed to sustain this action.

\section{Acknowledgement}

This project is supported by a BRIDGES Grant from the International Diabetes Federation. BRIDGES, an International Diabetes Federation project, is supported by an educational grant from Lilly Diabetes.

\section{References}

1. Lobstein T, Frelut ML. Prevalence of overweight among children in Europe. Obes Rev. nov 2003;4(4):195-200.

2. Júlíusson PB, Roelants M, Eide GE, Hauspie R, Waaler PE, Bjerknes R. Overweight and obesity in Norwegian children: secular trends in weight-for-height and skinfolds. ActaPaediatr. 2007;96(9):1333-7.

3. Hossain P, Kawar B, El Nahas M. Obesity and diabetes in the developing world: a growing challenge. N Engl J Med. 2007;356(3):213-5.

4. Ghannem H, Fredj AH. Epidemiological transition and cardiovascular risk factors in Tunisia. Rev Epidemiol Sante Publique. 1997;45(4):286-92.

5. Ben Romdhane H, Skhiri H, Khaldi R, Oueslati A. Transition épidémiologique et transition alimentaire et nutritionnelle en Tunisie. Options Méditerranéennes. 2002;48:7-27. French.

6. Gaha R, Ghannem H, Harrabi I, Ben Abdelaziz A, Lazreg F, Fredj AH. Study of overweight and obesity in a population of urban school children in Sousse, Tunisia. Arch Pediatr. 2002;9(6):566-71.

7. Harrabi I, Maatoug Maaloul J, Ben Hammouda H, Gaha R, Lazreg F, Boussaadia A, et al. Tracking of overweight among urban school children: A 4 years cohort study in Sousse Tunisia. J Public Health Epidemiology. 2009;1(1):031-6.

8. Pedrosa C, Oliveira BM, Albuquerque I, Simões-Pereira C, Vaz-de -Almeida MD, Correia F. Metabolic syndrome, adipokines and ghrelin in overweight and obese schoolchildren: results of a 1-year lifestyle intervention programme. Eur J Pediatr. 2011;170(4):483-92. doi: 10.1007/s00431-010-1316-2.

9. Jamoussi H, Mahjoub F, Sallemi H, Berriche O, Ounaissa K, Amrouche C, et al. Metabolic syndrome in Tunisian obese children and adolescents. Tunis Med. 2012;90(1):36-40.

10. Messiah SE, Lipshultz SE, Natale RA, Miller TL. The imperative to prevent and treat childhood obesity: why the world cannot afford to wait. Clin Obes. 2013;3(6):163-71. doi: 10.1111/cob.12033.

11. Oude Luttikhuis H, Baur L, Jansen H, Shrewsbury VA, O’Malley C, Stolk $\mathrm{RP}$, et al. Interventions for treating obesity in children. Cochrane Database Syst Rev. 2009;(1):CD001872. doi: 10.1002/14651858.

12. Li XH, Lin S, Guo H, Huang Y, Wu L, Zhang Z et al. Effectiveness of a school-based physical activity intervention on obesity in school children: a nonrandomized controlled trial. BMC Public Health. 2014;14:1282. doi: 10.1186/1471-2458-14-1282.

13. Williams SL, Mummery WK. We can do that! Collaborative assessment of school environments to promote healthy adolescent nutrition and physical activity behaviors. Health Educ Res. 2015;30(2):272-84. doi: 10.1093/her/cyv007.

14. World Health Organization. WHO child growth standards: length/ height-for-age, weight-for-age, weight-for-length, weight-for-height and body mass index-for-age : methods and development (Internet). Geneva: World Health Organization, Department of Nutrition for Health and Development; 2006. (cited 2015 Jan20). Available from: http://www.who.int/childgrowth/standards/Technical_report.pdf

15.Zimmet PZ, Grundy SM, Eckel RH. The metabolic syndrome. Lancet. 2005;365(9468):1415-28.

16. Maggio ABR, Saunders Gasser C, Gal-Duding C, Beghetti M, Martin XE, 
Farpour-Lambert NJ, et al. BMI changes in children and adolescents attending a specialized childhood obesity center: a cohort study. BMC Pediatr. 2013;13:216. doi: 10.1186/1471-2431-13-216.

17. Barlow SE, Expert Committee. Expert committee recommendations regarding the prevention, assessment, and treatment of child and adolescent overweight and obesity: summary report. Pediatrics. 2007;120 Suppl 4:S164-92.

18. Lee A, Ho M, Keung VM, Kwong AC. Childhood obesity management shifting from health care system to school system: intervention study of school-based weight management programme. BMC Public Health 2014;14:1128. doi: 10.1186/1471-2458-14-1128.

19. McGuire S. Institute of Medicine. 2012. Accelerating progress in obesity prevention: solving the weight of the nation. Washington, DC: the National Academies Press. Adv Nutr . 2012;3(5):708-9. doi: 10.3945/an.112.002733.

20. Katz DL. School-based interventions for health promotion and weight control: not just waiting on the world to change. Annu Rev Public Health. 2009;30:253-72. doi: 10.1146/annurev

21. Dobbins M, De Corby K, Robeson P, Husson H, Tirilis D. School-based physical activity programs for promoting physical activity and fitness in children and adolescents aged 6-18. Cochrane Database Syst Rev. 2009;(1):CD007651. doi: 10.1002/14651858.

22. Walter HJ, Vaughan RD, Armstrong B, Krakoff RY, Tiezzi L, McCarthy JF. Characteristics of users and nonusers of health clinics in inner-city junior high schools. J Adolesc Health. 1996;18(5):344-8.

23. Soleimanpour S, Geierstanger SP, Kaller S, McCarter V, Brindis CD. The role of school health centers in health care access and client outcomes. Am J Public Health. 2010;100(9):1597-603. doi: 10.2105/ AJPH.2009.186833.
24. McNall MA, Lichty LF, Mavis B. The impact of school-based health centers on the health outcomes of middle school and high school students. Am J Public Health. 2010;100(9):1604-10. doi: 10.2105/ AJPH.2009.183590.

25. Sussman AL, Montoya C, Werder O, Davis S, Wallerstein N, Kong AS. An adaptive CBPR approach to create weight management materials for a school-based health center intervention. J Obes. 2013;2013:978482. doi: $10.1155 / 2013 / 978482$.

26. Ho M, Garnett SP, Baur L, Burrows T, Stewart L, Neve M, et al. Effectiveness of lifestyle interventions in child obesity: systematic review with meta-analysis. Pediatrics. 2012;130(6):e1647-71. doi: 10.1542/peds.2012-1176.

27. Aguilar Cordero MJ, Ortegón Piñero A, Mur Vilar N, Sánchez García JC, García Verazaluce JJ, García García I, et al. Physical activity programmes to reduce overweight and obesity in children and adolescents; a systematic review. Nutr Hosp. 2014;30(4):727-40. doi: 10.3305/nh.2014.30.4.7680.

28. Sharma M, Branscum P. Novel and emerging approaches to combat adolescent obesity. Adolesc Health Med Ther. 2010;1:9-19. doi: 10.2147/AHMT.S7579.

29. Jelalian E, Boergers J, Alday CS, Frank R. Survey of physician attitudes and practices related to pediatric obesity. ClinPediatr(Phila) 2003;42(3):235-45.

30. Sussman AL, Williams RL, Leverence R, Gloyd PW Jr, Crabtree BF. The art and complexity of primary care clinicians' preventive counseling decisions: obesity as a case study. Ann Fam Med. 2006;4(4):327-33.

31. Waters E, de Silva-Sanigorski a, Hall BJ, Brown T, Campbell KJ, GAO $\mathrm{Y}$, et al. Interventions for preventing obesity in children. Cochrane Database Syst Rev. 2011;(12):CD001871. doi: 10.1002/14651858. 